\title{
Kajian Efisiensi Produktifitas Alat Berat pada Proyek Jalan (Studi kasus: Ruas Jalan Mendalo Darat (Sp.Tiga)-Bts.Kota Jambi)
}

\author{
Elvira Handayani ${ }^{1}$, Firman Akbar ${ }^{2}$ \\ ${ }^{1}$ Dosen Fakultas Teknik Universitas Batanghari \\ ${ }^{2}$ Mahasiswa Teknik Sipil Universitas Batanghari \\ Correspondence email: elvira.handayani2@yahoo.co.id
}

\begin{abstract}
Abstrak. Produktifitas dan waktu kerja suatu alat berat merupakan salah satu faktor yang sangat penting dalam menentukan keberhasilan suatu proyek kontruksi agar dapat mengurangi keterlambatan kerja yang menyebabkan pemborosan biaya.Tujuan penelitian ini untuk mengetahui nilai produktifitas dan waktu kerja alat berat pada proyek jalan di ruas jalan Mendalo Darat (Sp.Tiga) - Bts. Kota Jambi. Alat berat yang akan dianalisa dalam penelitian ini adalah tandem roller merk Jumma, pneumatic tyred roller merk Sakai, pneumatic tyred roller merk Dynapac dan asphalt sprayer. Penelitian ini menggunakan metode perhitungan kapasitas produksi alat berat secara actual, yaitu perhitungan kecepatan alat berat, passing alat berat faktor efisiensi alat dan kapasitas produksi alat berat yang digunakan sesuai dengan yang terjadi di lapangan. Hasil analisis produktifitas alat berat dan waktu kerja yang diperoleh dari penelitian ini adalah tandem roller merk Jumma produktifitas sebesar $21,87 \mathrm{~m}^{3} / \mathrm{jam}$ dan waktu kerjanya 4 hari, pneumatic tyred roller merk Sakai sebesar 19,51 $\mathrm{m}^{3} / \mathrm{jam}$ dan waktu kerjanya 4 hari, pneumatic tyred roller merk Dynapac sebesar 17,58 $\mathrm{m}^{3} / \mathrm{jam}$ dan waktu kerjanya 4 hari, dan asphalt sprayer sebesar 19,51 $\mathrm{m}^{3} / \mathrm{jam}$ dan waktu kerjanya 4 hari.
\end{abstract}

Kata kunci: Produktifitas, waktu kerja, tandem roller, pneumatic tyred roller,asphalt prayer

\section{PEDAHULUAN}

Jalan raya merupakan prasarana tranportasi yang sangat efektif dan efisien yang dapat menunjang secara langsung perkembangan suatu wilayah baik perkotaan maupun pedesaan.Berdasarkan hal tersebut pemerintah mengusahakan agar perhubungan antar suatu daerah dengan daerah lainnya dapat berjalan dengan lancar, dalam hal ini Kementrian Pekerjaan Umum (P.U), memandang perlu melaksanakan proyek preservasi rehabilitasi jalan raya.

Study kasus yang diambil adalah ruas jalan Bts. Kota Jambi - Mendalo Darat (Sp. Tiga) dengan Panjang jalan 1450 meter, lebar jalan 7 meter dan tebal laston lapis aus modifikasi (AC-WC Mod) $4 \mathrm{~cm}$. Dalam bidang kontruksi, produktifitas suatu alat berat merupakan salah satu faktor yang sangat penting dalam menentukan keberhasilan suatu proyek kontruksi agar sesuai dengan jadwal yang telah direncanakan. Waktu kerja alat berat penting untuk diperhitungkan karena dapat mengurangi keterlambatan kerja dan menghindari pemborosan biaya. Alat berat yang akan di analisa dalam penelitian ini adalah tandem roller merk Jumma, pneumatic tyred roller merk Sakai, pneumatic tyred roller merk Dynapac dan asphalt sprayer.

Adapun rumusan masalah penelitian ini, bagaimana nilai produktivitas dan waktu kerja yang dihasilkan masingmasing alat berat pada proyek jalan raya di ruas jalan Mendalo Darat(Sp.Tiga) - Bts.Kota Jambi.

Penelitian ini akan menjadi lebih jelas dan terarah, maka dilakukan batasan masalah dalam pembahasan tugas akhir dengan ketentuan-ketentuan sebagai berikut.

Penelitian ini dilakukan pada ruas jalan Mendalo Darat(Sp. Tiga) - Bts. Kota Jambi, dengan panjang jalan 1,45 $\mathrm{km}$, lebar jalan $7 \mathrm{~m}$ dan tebal lapisan $4 \mathrm{~cm}$.Objek penelitian berupa alat berat yang digunakan pada pekerjaan jalan, yaitu : tandem roller, pneumatic tyred roller merk sakai, pneumatic tyred roller merk dynapac, dan asphalt sprayer.Perhitungan efisiensi produktifitas alat berat hanya untuk tahap pekerjaan Laston Lapis Aus Modifikasi (ACWC Mod).Waktu kerja efektif pada proyek jalan raya di ruas jalan Mendalo Darat(Sp.Tiga) - Bts.Kota Jambi adalah 6 jam / hari.Variabel-variabel yang ditinjau antara lain efisiensi kerja alat berat, total waktu pelaksanaan setiap pekerjaan dan pengoperasian peralatan untuk mendapatkan produktivitas yang baik.

Jalan adalah jalur-jalur tanah di atas permukaan bumi yang sengaja dibuat oleh manusia dengan bentuk, ukuranukuran dan konstruksinya sehingga dapat digunakan untuk menyalurkan lalu lintas orang, hewan dan kendaraan yang mengangkut barang-barang dari tempat yang satu ke tempat yang lainnya dengan cepat dan mudah (Silvia Sukirman ,1999).

Menurut Wilopo (2011), manajemen pemilihan dan pengendalian alat berat adalah proses merencanakan, mengorganisir, memimpin dan mengendalikan alat berat untuk mencapai tujuan pekerjaan yang ditentukan.

Menurut Suryadharma dan Y. Wigroho (1993) dalam Jurnal Perbandingan Biaya Penggunaan Alat Berat Andri Gustiono (2010), Produktivitas dapat dibagi menjadi dua bagian :

Produktivitas Tenaga Kerja Selain dari tenaga - tenaga yang tersedia, pelaksana harus mencari tenaga kerja baru untuk mencukupi keperluan tenaga kerja. Hal ini mengharuskan untuk menghitung kebutuhan tenaga kerja yang dibutuhkan, seperti tenaga kerja berpendididkan tinggi, operator alat berat dan lain sebagainya yang tentunya 
memerlukan suatu perencanaan sehingga pelaksanaan dapat berjalan dengan baik (Suryadharma dan Y. Wigroho ,1993). Produktivitas alat berat adalah batas kemampuan alat berat untuk bekerja. Hubungan antara tenaga yang dibutuhkan, tenaga yang tersedia dan tenaga yang dimanfaatkan sangat berpengaruh pada produktivitas suatu alat berat (Suryadharma dan Y. Wigroho ,1993). Sedangkan menurut Rostiyanti (2008), produktivitas adalah perbandingan antara hasil yang dicapai (output) dengan seluruh sumber daya yang digunakan (input). Produktivitas alat tergantung pada kapasitas dan waktu siklus alat (cycle time). Dengan demikian satu siklus alat berarti pula satu nilai produksi, sesuai dengan kapasitas alatnya. Cepat atau lambatnya waktu siklus akan sangat menentukan tinggi rendahnya produktivitas. Rumus dasar untuk menghitung produktivitas alat adalah :

produktivitas $=\frac{\text { Kapasitas }}{C T}$

\section{Tandem Roller}

Menurut Rochmanhadi (1992), tandem roller ini adalah alat yang memberikan lintasan yang sama pada masingmasing rodanya, beratnya antara 8 sampai 14 ton. Penambahan yang diakibatkan oleh pengisian zat cair (ballasting) berkisar antara 25\% hingga 60\% dari pada berat penggilas. Untuk mendapatkan penambahan kepadatan pada pekerjaan penggilasan biasanya digunakan three axle roller, penggunaan tandem roller pada penggilas batu-batuan yang keras dan tajam, sebaiknya jangan digunakan sebab akan merusak roda-roda penggilasnya. Butir-butir aspal cenderung mengisi bagian-bagian kosong yang terdapat diantara butir-butirnya. Akibat pemadatan ini aspal menjadi padat, dengan susunan yang lebih kompak. Untuk menghitung produktivitas tandem roller dapat dihitung menggunakan rumus berikut: (Rochmanhadi, 1992)

$P=\frac{W \times S \times L}{N} \times E$

Keterangan :

$\mathrm{P}=$ Produktifitas kerja tandem roller $\left(\mathrm{m}^{3} / \mathrm{jam}\right)$

$\mathrm{W}=\quad$ Lebar Roller $(\mathrm{m})$

$\mathrm{S}=$ Kecepatan gerak alat $(\mathrm{km} / \mathrm{jam})$

$\mathrm{L}=$ Tebal pemadatan $(\mathrm{m})$

$\mathrm{N}=$ Jumlah gerak bolak balik

$\mathrm{E}=$ Efisiensi kerja alat

\section{Pneumatic tyred roller}

Menurut Rochmanhadi (1992), pneumatic tyred roller ini adalah roda -roda penggilas. Jenis ini terdiri atas roda-roda dan karet yang di pompa pneumatic susunan dari roda muka dan roda belakang selang-seling sehingga bagian yang tidak tergilas oleh roda bagian muka, maka akan digilas oleh roda bagian belakang. Roda-roda ini menghasilkan apa yang dinamakan kneading action (tekanan) terhadap tanah sehingga membantu konsolidasi tanah.

Untuk menghitung produktivitas pneumatic tyred roller dapat dihitung menggunakan rumus berikut : (Rochmanhadi ,1992)

$P=\frac{W \times S \times L}{N} \times E$

Keterangan :

$\mathrm{P} \quad=$ Produktifitas kerja pneumatic tyred roller $\left(\mathrm{m}^{3} / \mathrm{jam}\right)$

$\mathrm{W}=$ Lebar Roller $(\mathrm{m})$

$\mathrm{S} \quad=$ Kecepatan gerak alat $(\mathrm{km} / \mathrm{jam})$

$\mathrm{L} \quad=$ Tebal pemadatan (m)

$\mathrm{N} \quad=$ Jumlah gerak bolak balik

$\mathrm{E} \quad=$ Efisiensi kerja alat

\section{Asphalt Sprayer}

Menurut Rochmanhadi (1992), asphalt sprayer adalah mesin penyemprotan aspal cair (prime coat). Penyemprotan ini dilakukan setelah permukaan jalan dibersihkan. Aspal yang dikeluarkan oleh mesin ini bukan hanya mengalir begitu saja melainkan disemprot dengan kuat akan ditutupi dengan sempurna.

Untuk menghitung produktivitas asphalt sprayer dapat dihitung menggunakan rumus berikut: (Rochmanhadi , 1992) 


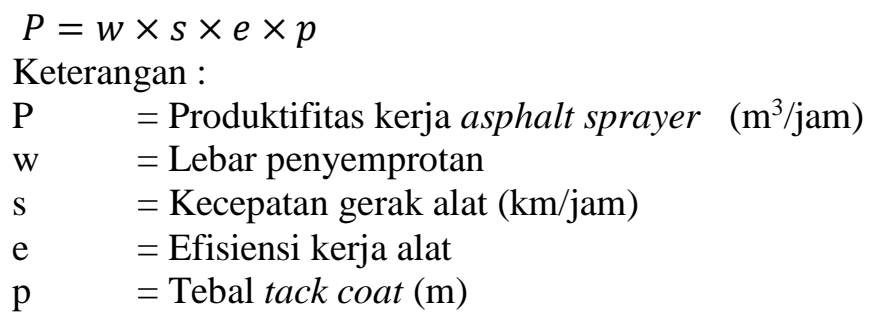

\section{Efisiensi Alat Berat}

Dalam pelaksanaan pekerjaan dengan menggunakan alat berat terdapat faktor yang mempengaruhi produktifitas alat (E). Bagaimana efektifitas alat tersebut berkerja tergantung dari beberapa hal yaitu : (Rostiyanti, 2008)

1. Kemampuan operator memakai alat

2. Pemilihan dan pemakaian alat

3. Perenacanaan dan pengaturan tata letak

4. Topografi dan volume perkerjaan

5. Kondisi cuaca

6. Metode pelaksanaan alat

Cara umum yang dipakai untuk menentukan efisiensi alat adalah dengan menghitung beberapa menit alat itu berkerja efektif dalam satu jam. Contohnya jika dalam satu jam waktu efektif alat berkeja adalah 45 menit maka dapat dikatakan efisiensi alat adalah 45/60 $=0,75$.

Efisiensi alat $=\frac{\text { jam kerja efektif }}{60}$

Tabel 1. Faktor Kondisi Pekerjaan Dan Kondisi Tata Laksana

\begin{tabular}{ccccc}
\hline \multirow{2}{*}{ Kondisi Pekerjaan } & \multicolumn{4}{c}{ Kondisi tata laksana } \\
\cline { 2 - 4 } & Baik sekali & Baik & Sedang & Buruk \\
\hline Baik sekali & 0,84 & 0,81 & 0,75 & 0,70 \\
Baik & 0,78 & 0,75 & 0,71 & 0,65 \\
Sedang & 0,72 & 0,69 & 0,65 & 0,60 \\
Buruk & 0,63 & 0,61 & 0,57 & 0,52 \\
\hline
\end{tabular}

Sumber : Rochmanhadi, 1992

\section{Waktu Pengerjaan Alat Berat}

Dalam melaksanakan suatu pekerjaan tentu dibatasi oleh waktu, sehingga alat berat sangat membantu untuk mempercepat pelaksanaan pekerjaan yang tentu saja dengan volume yang besar.

Waktu pelaksanaan pekerjaan adalah jangka waktu pelaksanaan dari seluruh kegiatan yang dihitung dari permulaan kegiatan sampai dengan seluruh kegiatan berakhir. Waktu pelaksanaan pekerjaan diperoleh dari penjumlahan waktu yang dibutuhkan untuk menyelesaikan seluruh item pekerjaan.

Waktu pengerjaan alat berat digunakan untuk mengetahui berapa lama alat bekerja. Untuk menghitung waktu pengerjaan menggunakan volume, produktivitas alat dan jumlah alat.

Seperti yang terdapat pada rumus dibawah ini : (Rostiyanti ,2008)

Waktu pengerjaan $=\frac{\text { volume }_{\text {pekerjaan }}}{\text { produktifitas }_{\text {terkecil }}}$

\section{METODE}

Metode penelitian adalah langkah-langkah dan rencana dari proses berpikir dan memecahkan masalah mulai dari penelitian pendahuluan, penemuan masalah, pengamatan, pengumpulan data baik dari referensi tertulis maupun observasi langsung dilapangan, melakukan pengelolahan dan interpretasi data sampai penarikan kesimpulan atas permasalahan yang diteliti. Proses penelitian dimulai menemukan dan mengenali permasalahan yang ada, dengan menggunakan tinjauan pustaka untuk sejauh mana tinjauan terdapat masalah yang akan ditelit. Spesifikasi volume pekerjaan Laston Lapis Aus Modifikasi (AC-WC Mod) yang diteliti adalah $406 \mathrm{~m}^{3}$ dengan lebar jalan 7 meter dengan ketebalan $4 \mathrm{~cm}$ dan panjang 1,45 km. 


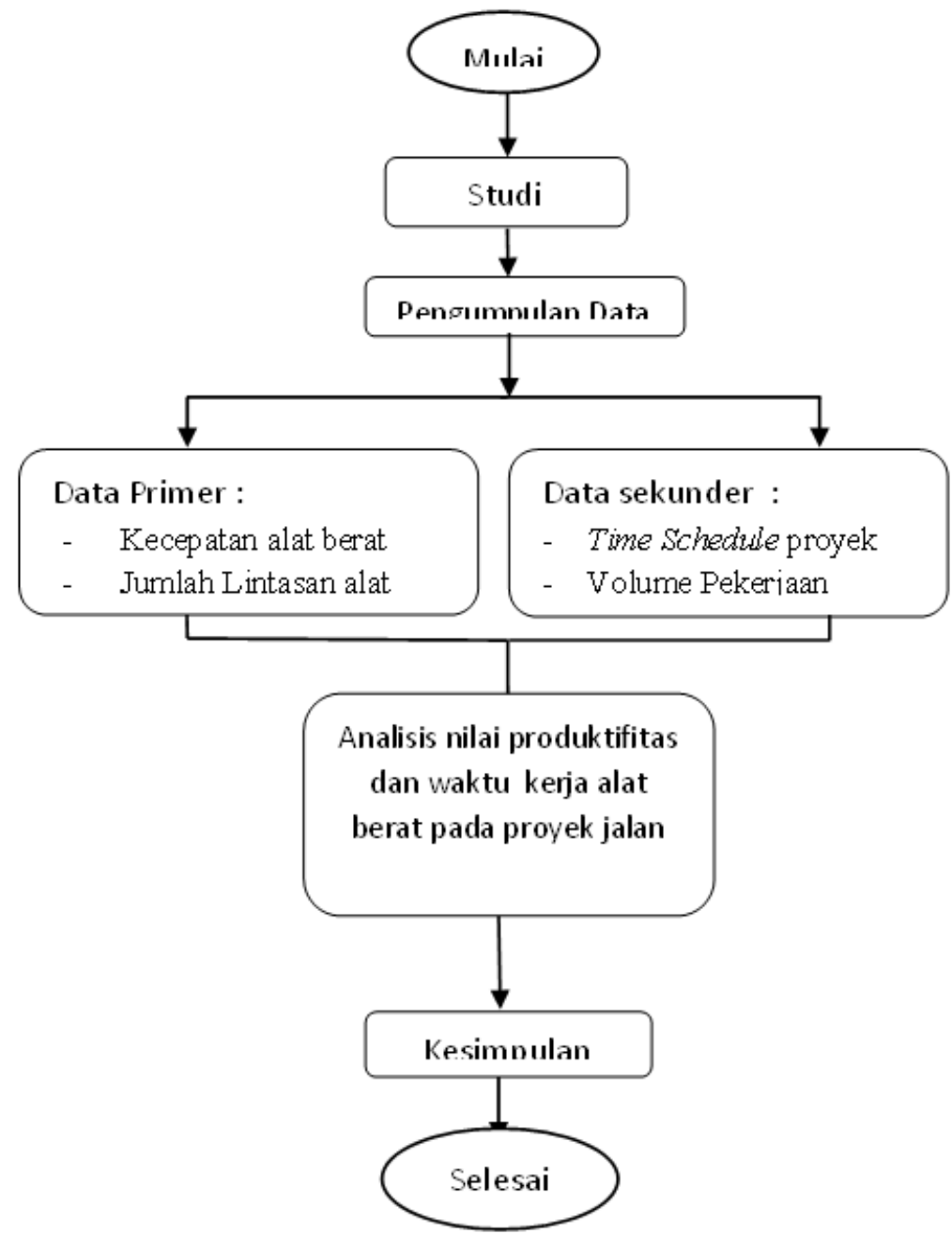

Gambar 1. Bagan Alir Penelitian

Sumber: Data Olahan (2019)

\section{HASIL DAN PEMBAHASAN}

Pekerjaan dalam proyek preservasi rehabilitasi jalan Sp. Tuan- Mendalo Darat (Sp. Tiga)- Bts. Kota Jambi/ Sp.Rimbo - Tempino - Bts. Sumsel ini tidak terlepas dari digunakannya alat berat sebagai sarana untuk mempermudah pekerjaan. Namun sebelum melaksanakan pekerjaan tersebut perlu diperhitungkan kapasitas produksi masing-masing alat yang bekerja untuk setiap jenis pekerjaan.

Berikut ini adalah perhitungan kapasitas produksi alat berat alat berat yang digunakan untuk menyelesaikan pekerjan Laston Lapis Aus Modifikasi (AC-WC Mod) dilapangan :

\section{Tandem Roller}

Perhitungan produktivitas tandem roller untuk pekerjan Laston Lapis Aus Modifikasi (AC-WC Mod). Adapun perhitungannya sebagai berikut :

Merek dan model alat = JUMMA 2YJ8/10 tahun 2018

Lebar roller $(\mathrm{B}) \quad=1,45 \mathrm{~m}$

Lebar Efektif $(\mathrm{Be}) \quad=1,25 \mathrm{~m}$

Kecepatan alat $(\mathrm{V}) \quad=4,498 \mathrm{~km} / \mathrm{jam}$

Efisiensi alat $(\mathrm{E}) \quad=0,75$

Jumlah lintasan $(\mathrm{N}) \quad=6$

Tebal pemadatan $(\mathrm{t}) \quad=0,04 \mathrm{~m}$

$\mathrm{P}=\frac{\mathrm{Be} \times \mathrm{V} \times \mathrm{t}}{\mathrm{N}} \times \mathrm{E}$

$\mathrm{P}=\frac{1,25 \times 4,498 \times 1000 \times 0,04}{6} \times 0,75$

$\mathrm{P}=21,87 \mathrm{~m}^{3} / \mathrm{jam}$ 
Elvira Handayani dan Firman Akbar, Kajian Efisiensi Produktifitas Alat Berat pada Proyek Jalan (Studi kasus: Ruas Jalan Mendalo Darat (Sp.Tiga)-Bts.Kota Jambi)

Perhitungan waktu kerja tandem roller untuk pekerjan Laston Lapis Aus Modifikasi (AC-WC Mod). Adapun perhitungannya sebagai berikut :

Produktifitas tandem roller $\quad: 21,87 \mathrm{~m}^{3} / \mathrm{jam}$

Volume pekerjaan $\quad: 406 \mathrm{~m}^{3}$

Waktu kerja alat $=\frac{\text { volume pekerjaan }}{\text { produktifitas tandem roller }}$

Waktu kerja alat $=\frac{406 \mathrm{~m}^{3}}{21,87 \mathrm{~m}^{3} / \mathrm{jam} \times 6 \text { jam } / \text { hari }}$

Waktu kerja alat $=3,1 \approx 4$ hari

Pneumatic Tyred Roller Sakai

Perhitungan produktivitas Pneumatic Tyred Roller untuk pekerjan Laston Lapis Aus Modifikasi (AC-WC Mod). Adapun perhitungannya sebagai berikut :

Merek dan model alat $=$ SAKAI T600C tahun 2018

Lebar roller $(\mathrm{B}) \quad=2,275 \mathrm{~m}$

Lebar Efektif $(\mathrm{Be}) \quad=1,975 \mathrm{~m}$

Kecepatan alat $(\mathrm{V}) \quad=5,926 \mathrm{~km} / \mathrm{jam}$

Efisiensi alat $(\mathrm{E}) \quad=0,75$

Jumlah lintasan $(\mathrm{N}) \quad=18$

Tebal pemadatan $(\mathrm{t}) \quad=0,04 \mathrm{~m}$

$\mathrm{P}=\frac{\mathrm{Be} \times \mathrm{V} \times \mathrm{t}}{\mathrm{N}} \times \mathrm{E}$

$\mathrm{P}=\frac{1,975 \times 5,926 \times 1000 \times 0,04}{18} \times 0,75$

$\mathrm{P}=19,51 \mathrm{~m}^{3} / \mathrm{jam}$

Perhitungan waktu kerja pneumatic tyred roller merk Sakai untuk pekerjan Laston Lapis Aus Modifikasi (ACWC Mod). Adapun perhitungannya sebagai berikut :

Produktifitas tandem roller $\quad: 19,51 \mathrm{~m}^{3} / \mathrm{jam}$

Volume pekerjaan $: 406 \mathrm{~m}^{3}$

Waktu kerja alat $=\frac{\text { volume pekerjaan }}{\text { produktifitas pneumatic tyred roller }}$

Waktu kerja alat $=\frac{406 \mathrm{~m}^{3}}{19,51 \mathrm{~m}^{3} / \mathrm{jam} \times 6 \text { jam } / \text { hari }}$

Waktu kerja alat $=3,47 \approx 4$ hari

Pneumatic Tyred Roller Dynapac

Perhitungan produktivitas Pneumatic Tyred Roller untuk pekerjan Laston Lapis Aus Modifikasi (AC-WC Mod). Adapun perhitungannya sebagai berikut :

Merek dan model alat $=$ DYNAPAC CP201W tahun 2018

Lebar roller $(\mathrm{B}) \quad=2,073 \mathrm{~m}$

Lebar Efektif $(\mathrm{Be}) \quad=1,773 \mathrm{~m}$

Kecepatan alat $(\mathrm{V}) \quad=5,949 \mathrm{~km} / \mathrm{jam}$

Efisiensi alat $(\mathrm{E}) \quad=0,75$

Jumlah lintasan $(\mathrm{N}) \quad=18$

Tebal pemadatan $(\mathrm{t}) \quad=0,04 \mathrm{~m}$

$\mathrm{P}=\frac{\mathrm{Be} \times \mathrm{V} \times \mathrm{t}}{\mathrm{N}} \times \mathrm{E}$

$\mathrm{P}=\frac{1,773 \times 5,949 \times 1000 \times 0,04}{18} \times 0,75$

$\mathrm{P}=17,58 \mathrm{~m}^{3} / \mathrm{jam}$

Perhitungan waktu kerja pneumatic tyred roller merk Dynapac untuk pekerjan Laston Lapis Aus Modifikasi (AC-WC Mod). Adapun perhitungannya sebagai berikut :

Produktifitas tandem roller $\quad: 17,58 \mathrm{~m}^{3} / \mathrm{jam}$

Volume pekerjaan $\quad: 406 \mathrm{~m}^{3}$ 
Elvira Handayani dan Firman Akbar, Kajian Efisiensi Produktifitas Alat Berat pada Proyek Jalan (Studi kasus: Ruas Jalan Mendalo Darat (Sp.Tiga)-Bts.Kota Jambi)

$\begin{aligned} \text { Waktu kerja alat } & =\frac{\text { volume pekerjaan }}{\text { produktifitas pneumatic tyred roller }} \\ \text { Waktu kerja alat } & =\frac{406 \mathrm{~m}^{3}}{17,58 \mathrm{~m}^{3} / \text { jam } \times 6 \mathrm{jam} / \text { hari }} \\ \text { Waktu kerja alat } & =3,85 \approx 4 \text { hari }\end{aligned}$

Asphalt Sprayer

Perhitungan produktivitas Asphalt Sprayer untuk pekerjan Laston Lapis Aus Modifikasi (AC-WC Mod). Adapun perhitungannya sebagai berikut :

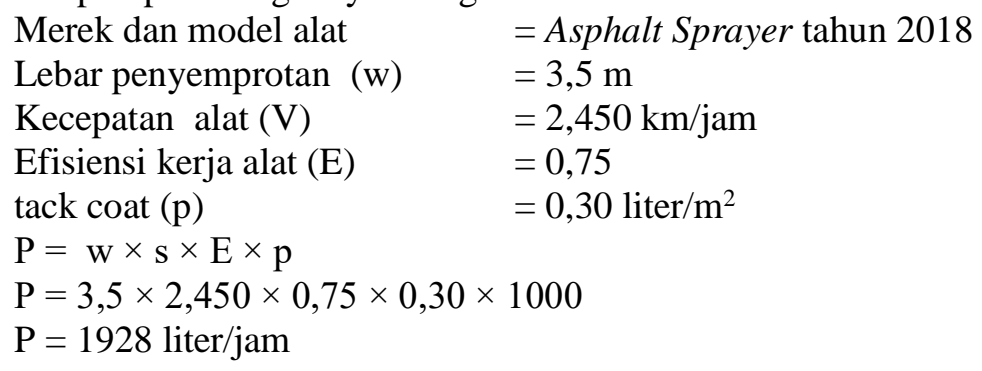

Perhitungan waktu kerja asphalt sprayer untuk pekerjan Laston Lapis Aus Modifikasi (AC-WC Mod). Adapun perhitungannya sebagai berikut :

$\begin{array}{lc}\text { Produktifitas asphalt sprayer } & : 1928 \text { liter/jam } \\ \text { Volume pekerjaan } & : 3045 \text { liter } \\ \text { Waktu kerja alat }= & \frac{\text { volume pekerjaan }}{\text { produktifitas asphalt sprayer }} \\ \text { Waktu kerja alat }= & \frac{3045 \text { liter }}{1928 \text { liter/jam } \times 6 \text { jam } / \text { hari }} \\ \text { Waktu kerja alat }= & 3,8 \approx 4 \text { hari }\end{array}$

Tabel 2. Penggunaan alat berat berdasarkan volume, waktu dan produktifitas

\begin{tabular}{cccccc}
\hline No & Nama Alat berat & Volume & Produktifitas Alat Berat & Waktu kerja pehitungan & Waktu kerja real \\
\hline $\mathbf{1}$ & Tandem Roller & $406 \mathrm{~m}^{3}$ & $21,87 \mathrm{~m}^{3} / \mathrm{jam}$ & 4 hari & $4 \mathrm{hari}$ \\
$\mathbf{2}$ & $\begin{array}{c}\text { Pneumatic Tyred } \\
\text { Roller Sakai }\end{array}$ & $406 \mathrm{~m}^{3}$ & $19,51 \mathrm{~m}^{3} / \mathrm{jam}$ & 4 hari & 4 hari \\
$\mathbf{3}$ & $\begin{array}{c}\text { Pneumatic Tyred } \\
\text { Roller Dynapac }\end{array}$ & $406 \mathrm{~m}^{3}$ & $17,58 \mathrm{~m}^{3} / \mathrm{jam}$ & 4 hari & $4 \mathrm{hari}$ \\
$\mathbf{4}$ & Aspalt Sprayer & 3045 liter & $1928 \mathrm{liter} / \mathrm{jam}$ & 4 hari & 4 hari \\
\hline
\end{tabular}

Sumber :Data Olahan, 2019

\section{SIMPULAN}

1. Pada pekerjaan Laston Lapis Aus Modifikasi (AC-WC Mod), alat berat yang digunakan ada 1 (unit) tandem roller, 2 (unit) pneumatic tyred roller, dan 1 (unit) asphalt sprayer.

2. Nilai produktifitas 1 (unit) alat berat tandem roller merk Jumma adalah $21,87 \mathrm{~m}^{3} / \mathrm{jam}$ dengan volume perkerjaan $406 \mathrm{~m}^{3}$ dan waktu kerja adalah 4 hari. 2 (unit) pneumatic tyred roller adalah

3. Nilai produktifitas pneumatic tyred roller merk sakai adalah $19,51 \mathrm{~m}^{3} / \mathrm{jam}$ dengan volume $406 \mathrm{~m}^{3}$ dan waktu kerja 4 hari dan nilai produktifitas pneumatic tyred roller merk Dynapac adalah 17,58 $\mathrm{m}^{3} / \mathrm{jam}$ dengan volume $406 \mathrm{~m}^{3}$ dan waktu kerja 4 hari.

4. Nilai produktifitas 1 (unit) ashpalt sprayer adalah 1928 liter/jam dengan volume 3045 liter dan waktu kerja 4 hari.

5. Hasil perhitungan yang didapat sama dengan waktu sebenarnya di lapangan karena pekerjaannya di kerjakan sesuai prosedur dan faktor-faktor penghabat pekerjaan di lapangan seperti cuaca, medan yang di tempuh sangat baik

\section{DAFTAR PUSTAKA}

Kementerian Pekerjaan Umum. 2013. Pedoman Bahan Konstruksi Bangunan dan Rekayasa Sipil. Jakarta: Kementerian Pekerjaan Umum.

Kholil, Ahmad. 2012. Alat Berat. Bandung: PT. Remaja Rosdakarja Offset

Nabar, Darmansyah. 1998. Pemindahan Tanah Mekanis dan Alat Berat. Palembang: Universitas Sriwijaya. 
Elvira Handayani dan Firman Akbar, Kajian Efisiensi Produktifitas Alat Berat pada Proyek Jalan (Studi kasus: Ruas Jalan Mendalo Darat (Sp.Tiga)-Bts.Kota Jambi)

Rochmanhadi. 1992. Alat-Alat Berat dan Penggunaannya. Jakarta: YBPPU

Rostiyanti, Susi Fatena. 2008. Alat Berat Untuk Proyek Konstruksi. Jakarta: Rineka Cipta.

Tenriajeng, Andi Tenrisukki. 2003. Pemindahan Tanah Mekanis. Jakarta: Gunadarma.

Kementerian Pekerjaan Umum. 2010. Dokumen Spesifikasi umum. Jakarta: Kementerian Pekerjaan Umum.

Wilopo, Djoko. 2009. Metode Konstruksi dan Alat-Alat Berat. Jakarta: Universitas Indonesia 